\title{
Study of Effects of Low Doses UV Radiation on Microporous Polysulfone Membranes in Sterilization Process
}

\author{
Ni Nyoman Rupiasih ${ }^{1}$, Hery Suyanto ${ }^{2}$, Made Sumadiyasa ${ }^{2}$, Nyoman Wendri ${ }^{2}$ \\ ${ }^{1}$ Biophysics Lab, Department of Physics, University of Udayana, Denpasar, Indonesia \\ ${ }^{2}$ Aplied-Physics Lab, Department of Physics, University of Udayana, Denpasar, Indonesia \\ Email: rupiasih69@yahoo.com
}

Received October 27, 2012; revised November 30, 2012; accepted December 9, 2012

\begin{abstract}
Synthetic membranes have gained an important place in chemical technology and are used in a broad range of applications. UV irradiation is an age old process used for disinfection as well as for sterilization purposes. It is used for sterilizing equipment in which polysulfone (PSf) membranes are used. As a result, short time UV irradiation of polymer membranes has acquired importance in recent times. In the present study, microporous polysulfone membranes with $0.108 \mathrm{~mm}$ thickness have been prepared using phase inversion method. Effect of UV irradiation on the membranes for short time intervals ( 0 - 60 minutes) has been investigated using UV-Vis and FTIR spectrophotometer, and SEM. The performance of the membranes has studied by filtration techniques. UV-Vis and IR spectra analysis and SEM images obtained suggest that chains scission and crosslink have occurred simultaneously in the irradiated membranes by UV radiation in a dose dependant manner. The pure water flux (PWF) values of irradiated membranes obtained from filtration studies were higher compared to that of the control membrane. These results show that a very short UV irradiation ( 2 minutes) affected the physicochemical characteristics of microporous polysulfone membrane which it increases with increase in time.
\end{abstract}

Keywords: Microporous Polysulfone Membrane; UV-Sterilization; Spectroscopy; Filtration; Physicochemical

\section{Introduction}

Membranes processes are becoming more and more important in chemical technology and are used in a broad range of applications. In a separation process, the goal is to allow one component of the mixture to permeate the membrane freely, while hindering permeation of other components. The main factors determining the membrane behaviour in a filtration process are the structure, chemical composition and the operation conditions. Structure involving pore size distribution or pore density and the active layer thickness are the main factors in determining the flux and retention $[1,2]$.

Radiation is widely used in the materials science especially polymers for surface modification, to improve bulk properties and sterilization. As such, UV radiation has long been used as a disinfectant as well as for sterilization of polymer-based medical devices and water purification [3-6]. It has been long known that many important physical and chemical properties of polymers can be modified with radiation. Among those are the molecular weight, chain length, polydispersity, branching and chain termination [7-9]. In this regard, understanding of how and to what extent these characteristics can be altered in relation to performance and utility of irradiated polymers is very important.

Many studies have been carried out in order to understand the mechanism of the basic processes of radiation effects on polymer membranes $[1,10]$. Chemical changes by UV exposure result in a complex set of processes involving a combined effect of UV and oxygen, in which formation of a complex mixture of products is observed [2]. Bond dissociation is initiated by the absorption of UV radiation, resulting in chain scission and/or crosslinking; subsequent reactions with oxygen result in the formation of functional groups such as carbonyl $(\mathrm{C}=\mathrm{O})$, carboxyl (COOH), or peroxide (O-O). The effects of UV exposure, or photo-degradation, are usually confined to the top few microns of the surface (50 - 100 microns) [7]. The effect of UV radiation is also compounded by the action of temperature, moisture, wind-borne abrasives, freeze-thaw and other environmental components. All UV light irradiation studies reported are mostly about the effect of long time interval exposures in the range from an hour to thousand hours.

Based on this background, it becomes clear that the 
studies carried out so far are related to the effect of long time exposure using spectroscopic analysis and surface structure imaging without considering the membrane performance. Therefore, study of short time interval UV irradiation of polymer membranes has acquired importance in recent times. The present study aims at giving a systematic overview of how and to what extent a very short UV irradiation ( 0 - 60 minutes) can alter the characteristics of PSf membrane, seen from the point of spectroscopic and imaging techniques and membrane performance. For this, membranes with $0.108 \mathrm{~mm}$ thickness were prepared by the phase inversion technique. The minimum and maximum time of exposure was fixed based on the surface structure image observed using SEM; they were below and above sterilization exposure time (10 minutes) [4-6]. The photo-degradation effects were studied and changes were observed using spectroscopic i.e. UV-Vis and FTIR and imaging i.e. SEM techniques. The performance of membranes was investigated in terms of flux i.e. pure water flux (PWF) using filtration technique. These irradiation studies were carried out to see the possible effects on the flux related characteristics of the microporous PSf membrane which is irradiated within very short time.

\section{Experimental}

\subsection{Preparation of the Membranes}

Polysulfone (PSf) resin was purchased from Aldrich $(18,224-3)$. The average molecular weight is 22,000 . The solvent, $N, N$-dimethylacetamide (DMAc) was purchased from Kemphasol (K04640); the molecular weight is 87.12. A solution of PSf in DMAc was prepared by mixing PSf and solvent and stirring the mixture for 24 48 hours to get a clear solution (dope solution). Dope solution was cast using phase inversion technique [11]. The flat sheet formed membranes were cut into different forms and sizes and were dried before being used as a sample.

\subsection{UV Irradiation Treatments}

Dried PSf membranes in the form of squares with area approximately $1 \mathrm{~cm}^{2}$ were irradiated by UV radiation in air at room temperature. Membranes were exposed to UV source (15 Watt Philips germicidal lamp) by keeping the distance between the source and sample constant at 10 $\mathrm{cm}$ where the intensity was $0.28 \mathrm{~W} \cdot \mathrm{m}^{-2}$. Membranes were exposed in varied times such as 2 minutes, 10 minutes, 15 minutes, 45 minutes and 60 minutes.

\subsection{Membranes Characterizations}

\subsubsection{UV-Vis and Fourier Transform Infrared (FTIR) Spectrophotometer}

Membranes in the form of squares with area approxi- mately $1 \mathrm{~cm}^{2}$ were cut from a flat sheet of dried membrane. UV-Vis absorption spectra of control (unirradiated) and irradiated membranes were recorded using a PerkinElmer spectrophotometer, model-330. The spectra were recorded in the 300 to $600 \mathrm{~nm}$ range. Similarly, IR spectra were recorded using a FTIR-8400 spectrophotometer (Shimadzu). The spectra were recorded in the 400 to $4000 \mathrm{~cm}^{-1}$ range.

\subsubsection{Scanning Electron Microscopy (SEM)}

Measurements were carried out using scanning electron microscopy (SEM, JEOL JSM-6360A) to characterize surface structure of the membranes. Dried membranes in square form and of area approximately $1 \mathrm{~cm}^{2}$ were coated with platinum for $45 \mathrm{~s}$ under vacuum condition by auto fine coater machine to make the membrane conducting and then were examined with SEM.

\subsubsection{Performance of the Membranes}

Dead-end filtration method was used to characterize the performance of control and irradiated membranes in term of pure water flux (PWF). Membranes in the form of circles with diameter approximately $6 \mathrm{~cm}$ were cut from the dried membranes (flat sheet form). They were kept in DW for around 1 hour before being used as a filter. The PWF was calculated using Equation (1).

$$
\operatorname{Flux}(\mathrm{J})=\frac{\text { volume of permeate }(\mathrm{L})}{\text { membrane } \operatorname{area}\left(\mathrm{m}^{2}\right) \times \operatorname{time}(\mathrm{h})}
$$

\section{Results and Discussions}

\subsection{Study of Chemical Changes in Polysulfone Membranes by Spectroscopic Techniques}

In the presence of air, the irradiation of PSf membranes by UV leads to important modifications in the UV-Vis and IR spectra of the exposed samples. The following changes were observed in the UV-Vis and IR spectra.

Figure 1 shows UV-Vis absorption spectra of control (unirradiated) and irradiated PSf membranes by UV radiation for different time intervals ( 0 - 60 minutes). For control membrane, it was observed that the absorbance increased with decrease in the wavelength. It increased sharply at wavelengths below $360 \mathrm{~nm}$. This is consistent with what has been reported earlier [12-14]. For the irradiated membranes, the absorption spectra show a marked increase in the absorption without any defined maximum extending from the near-UV region to the visible region (300 - $500 \mathrm{~nm})$. The yellowing color was observed in irradiated membranes with increase in exposure time $(0$ 60 minutes).

Figure 2 shows IR absorption spectra of control and irradiated membranes for various exposure times $(0-60$ minutes). The spectra obtained were similar to the spec- 


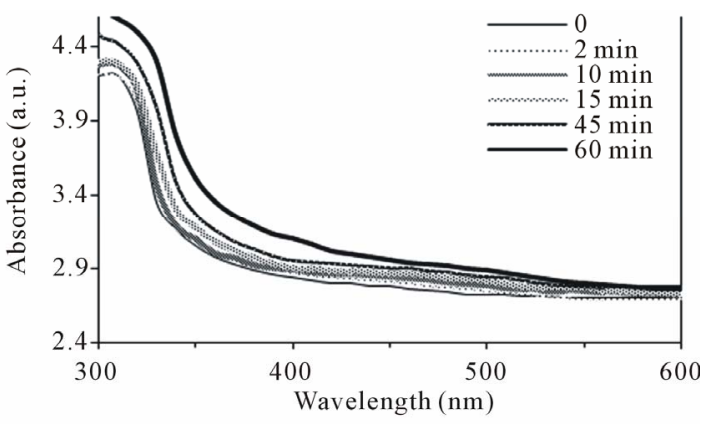

Figure 1. UV-Vis absorption spectra of control (unirradiated) and irradiated polysulfone membranes by UV radiation in air at room temperature with various exposure times (0 - 60 minutes).

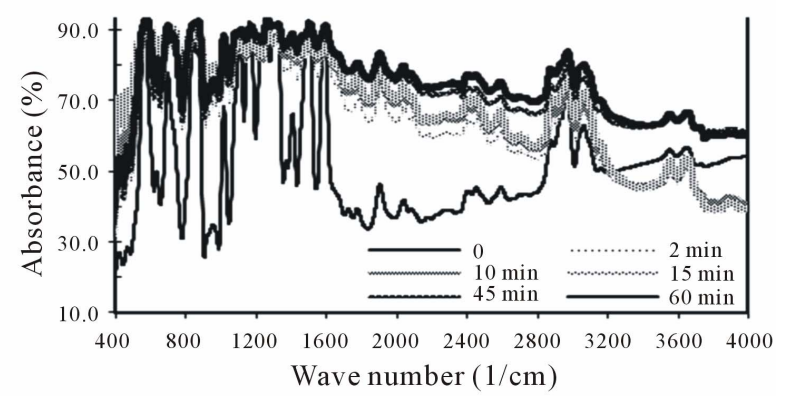

Figure 2. FTIR spectra of control (unirradiated) and irradiated polysulfone membranes by $U V$ radiation in air at room temperature with various exposure times $(0$ - 60 minutes).

tra that have been reported by other studies [14]. The characteristics of IR spectra for control membranes are described as follows. A peak at $\sim 1583 \mathrm{~cm}^{-1}$ (strong) is characteristic of $\mathrm{C}=\mathrm{C}$ stretching vibrations of aromatic rings, the peaks at $\sim 1148$ and $1294 \mathrm{~cm}^{-1}$ (strong) indicate the presence of sulfone $\left(\mathrm{SO}_{2}\right)$ groups. A broad band between $1500-1900 \mathrm{~cm}^{-1}$ indicate the presence of carbonyl $(\mathrm{C}=\mathrm{O})$ groups and the peaks at $\sim 2873,2966$ and $3094 \mathrm{~cm}^{-1}$ indicate the presence of $\mathrm{CH}_{3}$-symmetric aliphatic stretch, $\mathrm{CH}_{3}$-asymmetric aliphatic stretch and $\mathrm{C}-\mathrm{H}$ aromatic stretch respectively. The broad band in 2500 $3700 \mathrm{~cm}^{-1}$ region indicate the presence of hydroxyl groups (alcohol, phenol, acids) and the band in 1100 $1350 \mathrm{~cm}^{-1}$ region is characteristic of $\mathrm{C}-\mathrm{O}$ single bond. A peak at $\sim 699 \mathrm{~cm}^{-1}$ is characteristic of $-\mathrm{C}_{6} \mathrm{H}_{5}$ (phenyl groups) [2,8,12,15-17]. For irradiated membranes, the absorbance shows increase with increase in exposure time $(0,2,10,15,45$ and 60 minutes).

The changes occurred in different regions of IR spectra in case of the irradiated membranes. The subtraction of the spectra recorded from the control samples from that of irradiated samples permit the characterization of the modifications in the different regions (Figures 2-4).

After irradiation, following changes were observed in the IR spectra:
1) In the hydroxyl region $3100-3800 \mathrm{~cm}^{-1}$ (Figure 3), the difference in the absorbance increased with increase in exposure time. The formation of two maxima at $\sim 3120$ and $3730 \mathrm{~cm}^{-1}$ were observed as time increased which were attributed to the formation of phenolic groups. These observations suggested that the scission of the C-O bands or rearrangement of the ethers occurred due to exposure to UV radiation $[8,13,18]$.

2) In the carbonyl region $1500-1900 \mathrm{~cm}^{-1}$ (Figure 4), the formation of four maxima i.e. at $\sim 1540,1700,1755$ and $1830 \mathrm{~cm}^{-1}$ were observed. These maxima were attributed to the formation of carbonyl groups such as: carboxylate ion $\left(\mathrm{RCOO}^{-}\right)$, the $\mathrm{C}=\mathrm{O}$ strectching vibration of an amide group, carboxylic acids and derivative aliphatic carboxylic acids [8].

3) Figure 5 shows the difference in absorbance in the range $700-1500 \mathrm{~cm}^{-1}$ with increase in time. It was observed that many evolutions have been developed i.e. at $\sim 770,900,985,1040,1128,1195,1275,1310,1350$, 1385 and $1430 \mathrm{~cm}^{-1}$. These were the main evolutions observed which were related to the formation of benzenesulfonic acids $[8,14]$.

\subsection{Kinetic Study of Photooxidation}

Figure 6 shows increase in absorbance at $\sim 400 \mathrm{~nm}$ of

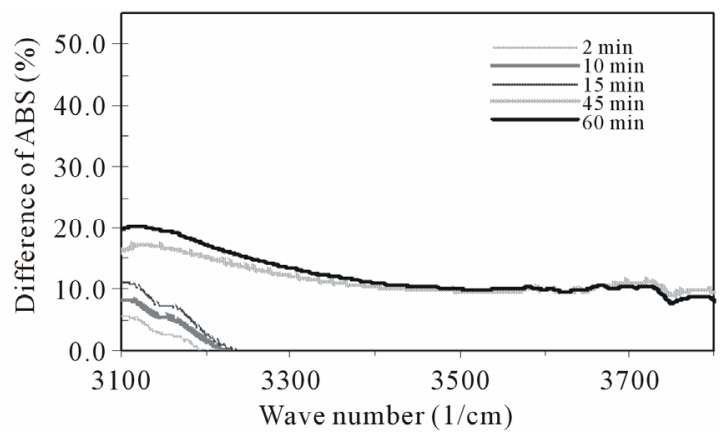

Figure 3. Subtracted FTIR spectra in the hydroxyl region (difference between irradiated and control) of polysulfone membranes for various exposure times ( 0 - 60 munites).

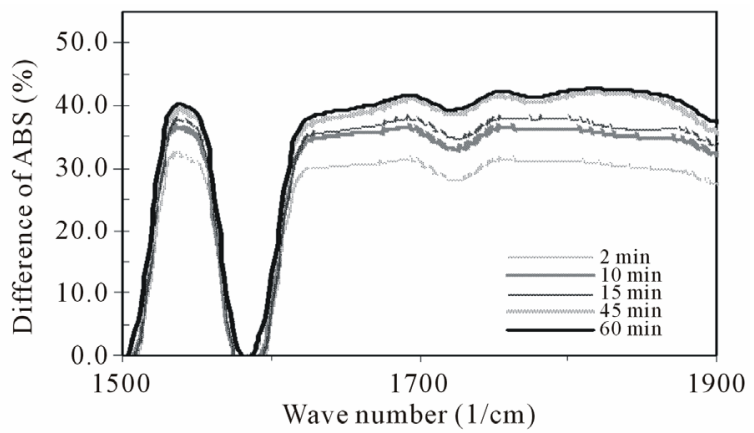

Figure 4. Subtracted FTIR spectra in the carbonyl region (difference between irradiated and control) of polysulfone membranes for various exposure times ( 0 - 60 minutes $)$. 


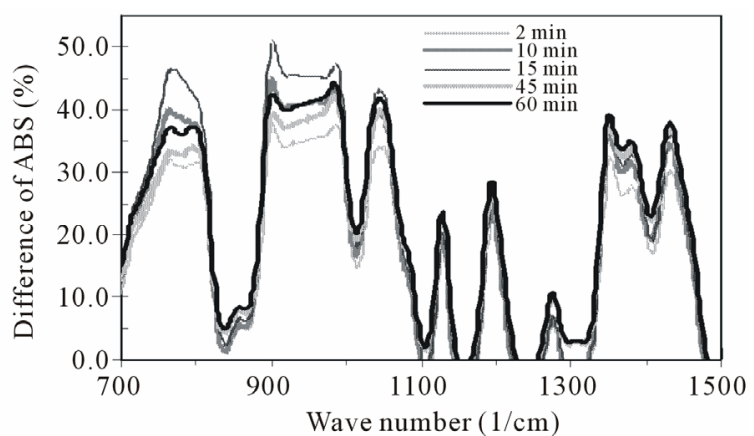

Figure 5. Subtracted FTIR spectra in the $700-1500 \mathrm{~cm}^{-1}$ region (difference between irradiated and control) of polysulfone membranes for various exposure times (0 - 60 minutes).

PSf membranes as a function of UV irradiation time (0 60 minutes). It was observed that the absorbance increased gradually as time increased from 0 to 45 minutes and increased sharply after 60 minutes exposure indicating greater damages to the membrane. This effect can be described as follows. The absorption of light by chromophoric phenylsulfone groups resulted in chain scissions. The scissions occurred in the first steps of the photodegradation leading to the formation of low molecular weight photoproducts $[8,12]$. This change can be attributed to the formation of carbonylated species in the irradiated membranes. Physically, this was observed by the increase of yellowing color in the irradiated membranes with increase in exposure time [15].

Figure 7 shows decrease in the absorption intensity at $\sim 1325 \mathrm{~cm}^{-1}$ with increase in exposure time $(0-60 \mathrm{~min}-$ utes). It was observed that the intensity decreased sharply from 0 to 45 minutes and remained stable at 60 minutes. The band at $\sim 1325 \mathrm{~cm}^{-1}$ was assigned to a convolution of backbone ether and sulfone which have been adopted for reliable kinetic investigation for the PSf polymer $[8,12]$. Such an observation confirmed that the photodegradation of PSf membrane involves the cleavage of the C-S and C-O bonds.

Figure 8 shows increase in the absorption intensity at $\sim 1725 \mathrm{~cm}^{-1}$ (carbonyl region) with increase in exposure time. It was observed that the intensity increased sharply from 0 to 2 minutes then gradually increased from 2 to 45 minutes and showed a slight decrease after 60 minutes exposure. This indicates increase in the amount of carbonyl formations and saturation occurred after 60 minutes exposure. Similar trend was observed in the hydroxyl region at $\sim 3250 \mathrm{~cm}^{-1}$ as shown in Figure 9.

Figure 10 shows decrease in the absorption intensity at $\sim 1385 \mathrm{~cm}^{-1}$ (hydrocarbon i.e. $\mathrm{CH}_{3}, \mathrm{CH}$ groups) with increase in exposure time. The intensity decreased gradually from 0 to 45 minutes and then abruptly decreased from 45 to 60 minutes. This indicates that dehydrogenation such as loss of hydrocarbon $\left(\mathrm{CH}_{3}, \mathrm{CH}\right)$ groups and

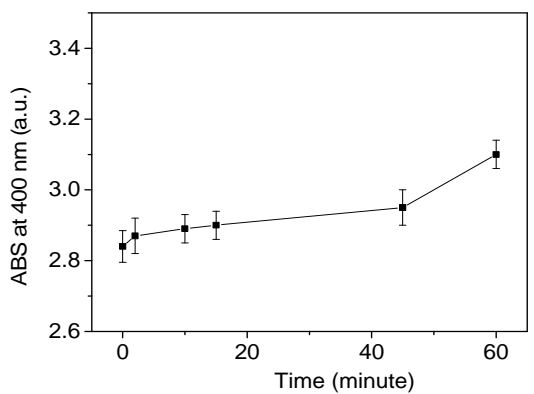

Figure 6. Increase in the absorbance at $400 \mathrm{~nm}$ of polysulfone membrane as a function of $\mathrm{UV}$ irradiation time $(0$ - 60 minutes).

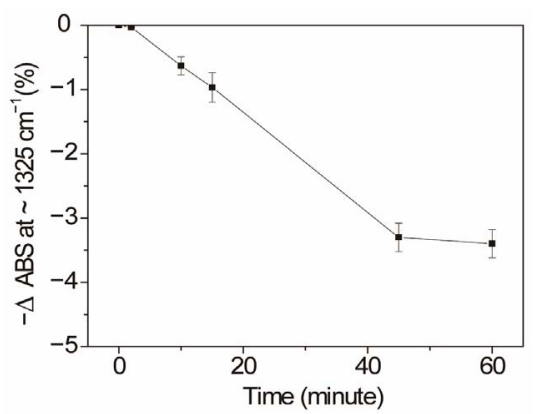

Figure 7. Decrease in the absorbance at $\sim 1325 \mathrm{~cm}^{-1}$ of polysulfone membrane as a function of UV irradiation time $(0$ 60 minutes).

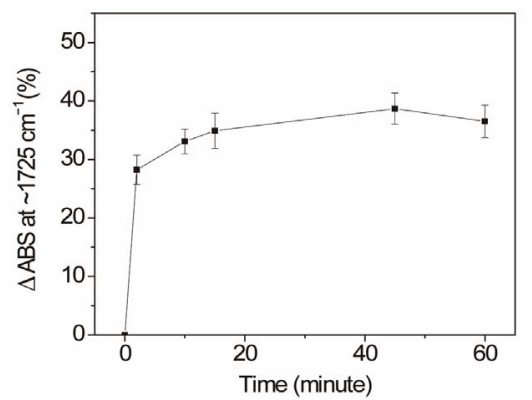

Figure 8. Increase in the absorbance in the carbonyl region $\left(\sim 1725 \mathrm{~cm}^{-1}\right)$ of polysulfone membrane as a function of $\mathrm{UV}$ irradiation time (0 - 60 minutes $)$.

degradation process of the paraffinic tails (loss of hydrogen) has occurred in irradiated membranes [12].

\subsection{Scanning Electron Microscopy (SEM) Images}

Figure 11 shows the surface structure of control and irradiated PSf membranes using SEM technique. It was observed that after 2 - 15 minutes exposure (Figures 11 (b)-(d)), the pore size increased and were more in number. After 45 minutes exposure (Figure 11(e)), ablations, cracks and debris were observed. The damage observed was more after 60 minutes exposure as shown in Figure 11(f). 


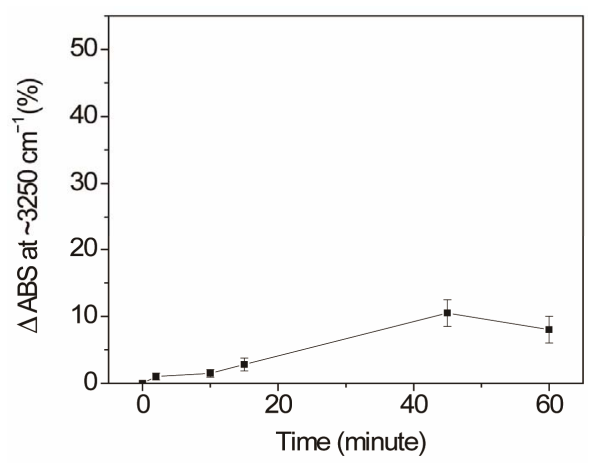

Figure 9. Increase in the absorbance in the hydroxyl region $\left(\sim 3250 \mathrm{~cm}^{-1}\right)$ of polysulfone membrane as a function of $\mathrm{UV}$ irradiation time ( 0 - 60 minutes $)$.

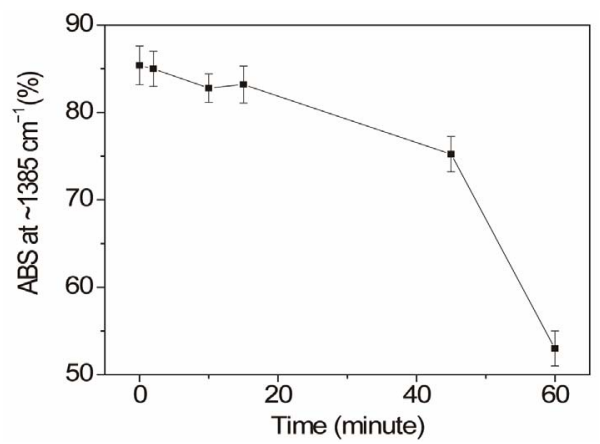

Figure 10. Decrease in the methyl absorption band at $\sim 1385$ $\mathrm{cm}^{-1}$ for polysulfone membranes as a function of UV irradiation time (0 - 60 minutes).

\subsection{Performance of the Membranes}

Figure 12 shows the PWF values of PSf membranes as a function of exposure time. It was observed that PWF values of irradiated membranes were higher than those of control membranes. The increase has been found to be about $225 \%-370 \%$. This result showed that the pore size of the irradiated membranes increased as compared to the control membranes. Also, ablation and cracks occurred for the higher exposure time from 45 to 60 minutes. However, the PWF values slightly decreased with increase in exposure time from 2 to 60 minutes.

\subsection{Discussions}

The UV-Vis spectra of control membranes showed that the light absorbed by the diphenylsulfone chromophoric units extends up to $325 \mathrm{~nm}$. Shorter wavelengths (300 $320 \mathrm{~nm}$ ) are totally absorbed by the membrane. This absorption property makes PSf membrane directly accessible to UV light which is present in terrestrial solar radiation.

UV-Vis and IR spectra analysis and SEM images obtained suggested that chains scission and crosslink had occurred simultaneously in the irradiated membranes by UV radiation which depends on the exposure time. The

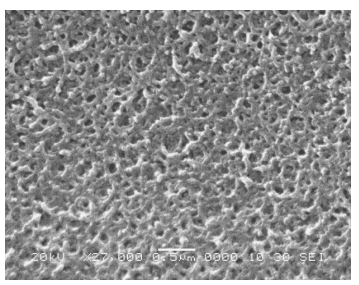

(a)

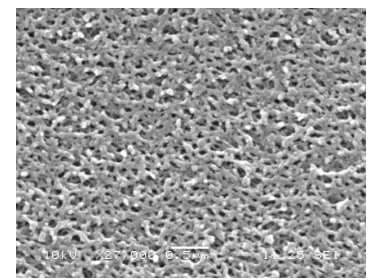

(c)

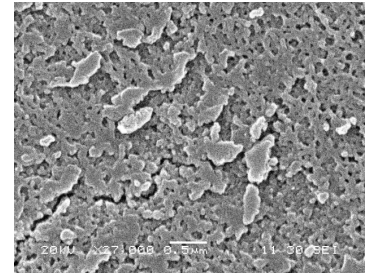

(e)

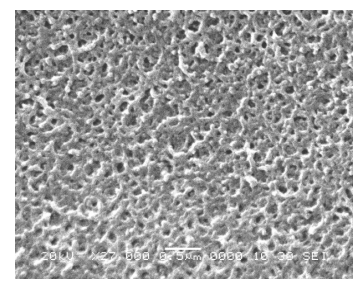

(b)

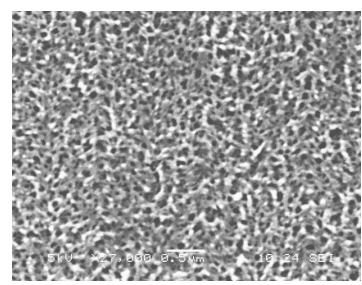

(d)

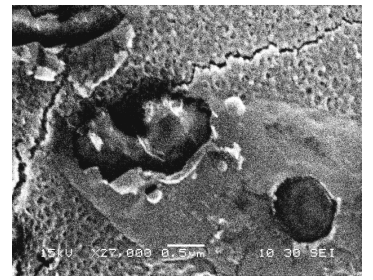

(f)
Figure 11. Effect of very short time of UV irradiation (0 - 60 minutes) on surface structure of polysulfone membranes observed using SEM. (a) Control and irradiated membranes; (b) 2 minutes; (c) 10 minutes; (d) 15 minutes; (e) 45 minutes and (f) 60 minutes.

photoproducts observed involve the formation of carbonylated species which are resulted from the oxidation and opening of phenyl rings $[8,12]$, the convolution of the backbone ether and sulfone, the oxidation of benzene rings and the increase in methyl groups.

The decrease observed in the absorption at $\sim 1325 \mathrm{~cm}^{-1}$ which is assigned to bond scissions of $\mathrm{C}-\mathrm{O}$ and $\mathrm{C}-\mathrm{S}$ (Figure 7) is in accordance with the formation of prevalent photoproducts resulting from the photodegradation of the diphenylethersulfones units such as carbonyl and hydroxyl products (Figures 8 and 9). It is also supported by IR spectra analyses for the hydrocarbon groups $\left(\sim 1385 \mathrm{~cm}^{-1}\right)$ that show the significant decrease in the absorption intensity (Figure 10) which reflected substantial damages.

These spectroscopic observations were supported by pore size and study of surface structure images of irradiated membranes observed using SEM. The changes occurred depend on the exposure time, Figure 11. Also, the interpretation is supported by the PWF values obtained from filtration studies. The PWF values of irradiated membranes were higher compared to the control membrane (Figure 12). For the shortest exposure time (2 minutes), the increase of PWF value was $\sim 370 \%$ and for the longest exposure time (60 minutes), it was $\sim 225 \%$, 


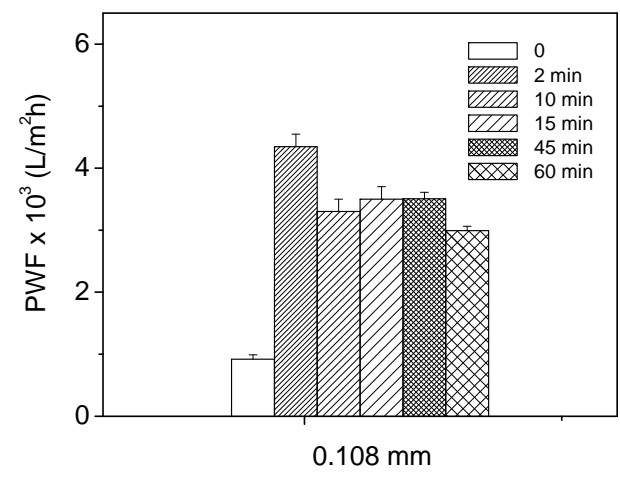

Figure 12. Effect of very short time of UV irradiation (0 - 60 minutes) on the PWF of polysulfone membranes measured using dead-end filtration method.

compared to the control membrane.

\section{Conclusion}

The effects of UV irradiation on PSf membranes with $0.108 \mathrm{~mm}$ thickness for very short exposure time (0 - 60 minutes) have been investigated. UV-Vis and IR spectra analysis and SEM images obtained suggest that chains scission and crosslink have occurred simultaneously in the irradiated membranes by UV radiation in a dose dependant manner. The PWF values of irradiated membranes obtained from dead-end filtration studies were higher compared to that of the control membrane. The study has demonstrated that the microstructure and the performance of PSf membrane were affected by UV irradiation within very short time of exposure (i.e. 2 minutes). This observation suggested that more care should be taken during the sterilization process and outdoor use of the membrane.

\section{Acknowledgements}

Ms. Ni Nyoman Rupiasih is grateful to Prof. P.B. Vidyasagar, Biophysics Lab. Dept. of Physics, University of Pune for the discussion and continuously supported in this work.

\section{REFERENCES}

[1] N. S. Allen and M. Edge, "Photodegradation and Photooxidation of Polymers, Fundamentals of Polymer Degradation and Stabilization," Elsevier Applied Science, Amsterdam, 1992.

[2] T. Yamashita, H. Tomitaka, T. Kudo, K. Horie and I. Mita, "Degradation of Sulfur-Containing Aromatic Polymers: Photodegradation of Polyethersulfone and Polysulfone," Polymer Degradation and Stability, Vol. 39, No. 1, 1993, pp. 47-54.

[3] S. Lerouge, A. C. Fozza, M. R. Wertheimer, R. Marchand and L. H. Yahia, "Sterilization by Low-Pressure Plasma: The Role of Vacuum-Ultraviolet Radiation," Plasma and
Polymers, Vol. 5, No. 1, 2000, pp. 31-46. doi:10.1023/A:1009504209276

[4] R. L. Clough, "High-Energy Radiation and Polymers: A Review of Commercial Processes and Emerging Applications," Nuclear Instruments and Methods in Physics Research $B$, Vol. 185, No. 1-4, 2001, pp. 8-33. doi:10.1016/S0168-583X(01)00966-1

[5] R. S. Benson, "Use of Radiation in Biomaterials Science," Nuclear Instruments and Methods in Physics Research B, Vol. 191, No. 1-4, 2002, pp. 752-757.

[6] J. L. Deal, "Ultraviolet Area Sterilizer and Method of Are Sterilization Using Ultraviolet Radiation," US Patent No. 6911177, 2005.

[7] J. W. Chin, T. Nguyen and K. Aouadi, "Effect of Environmental Exposure on Fiber-Reinforced Plastic (FRP) Materials Used in Construction," Journal of Composites Technology and Research, Vol. 19, No. 4, 1997, pp. 205213. doi:10.1520/CTR10120J

[8] A. Rivaton and J. L. Gardette, "Photodegradation of Polyethersulfone and Polysulfone," Polymer Degradation and Stability, Vol. 99, No. 3, 1999, pp. 385-403. doi:10.1016/S0141-3910(99)00092-0

[9] J. Pieracci, J. V. Crivello and G. Belfort, "Increasing Membrane Permeability of UV-Modified Poly(Ether Sulfone) Ultrafiltration Membranes," Journal of Membrane Science, Vol. 202, No. 1, 2002, pp. 1-16.

[10] N. N. Rupiasih and P. B. Vidyasagar, "Comparative Study of Effect of Low and Medium Dose Rate of $\gamma$ Irradiation on Microporous Polysulfone Membrane Using Spectroscopic and Imaging Techniques," Polymer Degradation and Stability, Vol. 93, No. 7, 2008, pp. 13001307. doi:10.1016/j.polymdegradstab.2008.04.003

[11] V. Kaiser and C. Stropnik, "Membranes from Polysulfone/ $N, N$-Dimethyl-Acetamide/Water System: Structure and Water Flux," Acta Chimica Slovenica, Vol. 47, No. 2, 2000, pp. 205-213.

[12] B. D. Gesner and P. G. Kelleher, "Thermal and PhotoOxidation of Polysulfone," Journal of Applied Polymer Science, Vol. 12, No. 5, 1968, pp. 1199-1206.

[13] N. S. Allen and J. F. Mc Kellar, "Photochemical Reactions in a Commercial Poly(Ether Sulfone)," Journal of Applied Polymer Science, Vol. 21, No. 5, 1977, pp. 11291135.

[14] B. D. Gesner and P. G. Kelleher, "Oxidation of Bisphenol a Polymers," Journal of Applied Polymer Science, Vol. 13, No. 10, 1969, pp. 2183-2191.

[15] L. Monney, C. Dubois and A. Chambaudet, "Ablation of the Organic Matrix: Fundamental Response of the PhotoAged Epoxy-Glass Fiber Composite," Polymer Degradation and Stability, Vol. 56, No. 3, 1998, pp. 357- 366. doi:10.1016/S0141-3910(96)00210-8

[16] D. S. Wavhal and E. R. Fisher, "Modification of Polysulfone Ultrafiltration Membrane by $\mathrm{CO}_{2}$ Plasma Treatment," Desalination, Vol. 172, No. 2, 2004, pp. 189-205. doi:10.1016/j.desal.2004.06.201

[17] A. Linares and J. L. Acosta, "Structural Characterization of Polymer Blends Based on Polysulfones," Journal of Applied Polymer Science, Vol. 92, No. 5, 2004, pp. 3030- 
3039. doi:10.1002/app.20263

[18] G. E. Schoolenberg and P. Vink, "Ultra-Violet Degradation of Polypropylene: 1. Degradation Profile and Thick- ness of the Embrittled Surface Layer," Polymer, Vol. 32, No. 3, 1991, pp. 432-437. 